\title{
PERSPECTIVE
}

\section{Tear lipocalin and the eye's front line of defence}

\author{
Anne-Marie Françoise Gachon, Eric Lacazette
}

Complex mechanisms are involved in mucosal defence at the air/epithelium interface. There are apparently two lines of protection. ${ }^{1}$ The first, which we are interested in here, prevents colonisation by micro-organisms on and through the epithelium. It is a non-inflammatory process, mainly mediated by (i) well known defence factors such as lysozyme and lactoferrin, (ii) specific secretory immunoglobulins A (sIgA), appropriate to surface protection, elicited by both local antigen administration and stimulation at related distal sites, and (iii) factors with cysteine proteinase inhibitor activity such as cystatin. Table 1 indicates the distribution of some of these proteins in several mucosal fluids. ${ }^{2-14}$ Together, these different factors keep potentially harmful micro-organisms and antigens out of the body. The second line of protection triggers an inflammatory response. This takes place when foreign material has penetrated the epithelium. It consists of a non-specific action of various systems and of a specific amplification of humoral and cellular immune response. Depending on the requirement of a particular body site, the composition of each secretion will be tuned appropriately to play numerous roles: wetting of the surface, exchange of gases, intake of nutrition and excretion of waste products, chemical and microbial defence, mechanical entrapment, and removal of potentially harmful micro-organisms and compounds.

The anterior part of the eye is protected by the mechanical action of blinking and the washing action of tears. The tear film maintains comfort and serves as the optical surface. Following the work of many researchers in this field, the classic concept of a three layered, aqueous dominated tear film ${ }^{15}$ has been replaced by the more likely concept of a mucin dominated gel,${ }^{16}$ hydrated by aqueous fluid containing electrolytes, small organic compounds, and many proteins. An inflammatory response in healthy eyes is rare and the tear fluid plays a significant role in protecting the eyes.

The first line of protection depends on the nature of the protein components present in the secretion: besides secretory IgA four proteins-lysozyme, lactoferrin, cystatin, and tear lipocalin - make up nearly $50 \%$ of the protein content. This site specific secretion composition enables tears to perform their protective function.

Lysozyme and lactoferrin properties have been known for a long time. Lysozyme is a powerful bacteriolytic agent, the specific action of which is the destruction of the cell walls of susceptible Gram positive bacteria; lactoferrin is an iron binding protein that impedes iron utilisation by bacteria and causes bacteriostasis as a result of its iron sequestering properties, but more than mere iron starvation may be involved in the antibacterial action of this protein.

An important cysteine proteinase inhibitor activity is present in tears. Proteinases are classified according to their catalytic mechanisms; serine proteinases, cysteine proteinases, aspartic proteinases, and metalloproteinases are among the recognised mechanistic classes. Different kinds of endogenous proteinase inhibitors are present in tissues and body fluids; their role is to regulate protein metabolism or protect tissues from proteolytic attacks by bacteria or viruses. The physiological activities of cysteine proteinases are controlled by a set of protein inhibitors that constitute the cystatin superfamily. Cystatins, like mucins, constitute a group of small proteins (MW around 14000 ) present in all mucosal secretions. In tears (and in saliva) the predominant cystatin is cystatin $\mathrm{S}$, but others are present. ${ }^{17-19}$ This has been clearly demonstrated by both immunological techniques (enzyme linked immunosorbent assay and immunoblots), and titrating papain, a cysteine proteinase of known specific activity, in the presence of tear fluid. Unlike the standard mechanism of action described for serine protease inhibitors (formation of a stable protein/proteinase inhibitor complex, followed by an irreversible hydrolysis at the inhibitor active site) the reaction of cystatin with the cysteine proteinase does not imply the formation of a covalent bond. The members of the cystatin superfamily (for a review see Henskens et $a l^{20}$ ) contain highly conserved domains (among these, $\mathrm{Q} x \mathrm{~V} x \mathrm{G}$ from 55 to 59 , and $\mathrm{W}$ at position 106) that participate in inhibition. These domains are located far apart in the amino acid sequence but are spatially contiguous on the surface of the protein, forming a wedge-shaped edge highly

Table 1 Tear proteins implicated in defence and their corresponding genes: tear lipocalin has recently been demonstrated to be expressed in the secretory cells of the tracheal epithelium. However, no data are at present available on its presence in the bronchial mucus

\begin{tabular}{|c|c|c|c|c|c|c|}
\hline \multirow[b]{2}{*}{ Protein } & \multicolumn{4}{|c|}{ Protein distribution } & \multirow[b]{2}{*}{ Corresponding gene } & \multirow[b]{2}{*}{ Chromosomal localisation } \\
\hline & Tears & Saliva & Nasal mucus & Bronchial mucus & & \\
\hline Lysozyme $^{14}$ & ++++ & + & ++++ & ++++ & $\mathrm{LYZ}^{2}$ & 12 \\
\hline Lactoferrin & ++++ & + & ++++ & ++++ & $\mathrm{LACT}^{3}$ & 3 \\
\hline Tear lipocalin (VEGP) & ++++ & + & $?$ & $+/-^{4}$ & $\mathrm{LCN} 1^{56}$ & $9 \mathrm{q} 34.3$ \\
\hline Secretory IgA ${ }^{14}$ & ++++ & +++ & ++++ & & & \\
\hline Immunoglobulin $A$ & & & & & $\mathrm{IGHA}^{7}$ & $14 \mathrm{q} 32.33$ \\
\hline Secretory component & & & & & SC or PIGR ${ }^{8}$ & $1 \mathrm{q} 31-\mathrm{q} 42$ \\
\hline $\mathcal{F}$ chain & & & & & $\mathrm{IGJ}^{9}$ & $4 \mathrm{q} 21$ \\
\hline Cystatin $\mathrm{S}^{14}$ & + & ++ & + & + & $\mathrm{CST}^{1011}$ & $20 \mathrm{p} 11.2$ \\
\hline Mucin & + & ++++ & ++++ & ++++ & MUC $1^{12}$ & $1 \mathrm{q} 21-24$ \\
\hline & & & & & MUC5AC ${ }^{13}$ & $11 \mathrm{p} 15$ \\
\hline
\end{tabular}


complementary to the active site of papain. The role of cystatins as proteinase inhibitors is well established.

Early this year, another protein, the tear lipocalin, was unexpectedly described by a Dutch team ${ }^{21}$ as playing a role in the non-immunological defence against microorganisms and viruses. Tear lipocalin (TL; MW 17 000, no glycosylation, tertiary structure unknown at present), is a protein present in large amounts in tears (about $20 \%$ of total protein content), and long considered tear specific. ${ }^{22}{ }^{23}$ Further interest was aroused when it was discovered that this protein, for which no function was clearly described, belonged to the lipocalin family. ${ }^{24-26}$ This family is composed predominantly of secreted proteins, with similar subunit molecular weights (around $20 \mathrm{kDa}$ ); comparison of the three dimensional structure of some of the members (their archetype is retinol binding protein, RBP) reveals striking secondary and tertiary structure homologies: a protein fold forming a $\beta$ barrel, consisting of two sets of four antiparallel $\beta$ strands and an $\alpha$ helix near the $\mathrm{C}$ terminus, provides a hydrophobic pocket. The available data indicate that their action, if not their sole function, is the binding of small hydrophobic molecules. ${ }^{27}$ One of the characteristics shared by the lipocalin family members is a very low level of sequence homology (25-30\%). This level might seem marginally significant, but allows different ligand specificities to be achieved by changing the residue types in the central cavity. Molecules with potentially hazardous biological effects can be safely transported from one cell to another: thus retinol and retinoids (bound to RBP, purpurin, $\beta$ lactoglobulin, $\alpha 1$ microglobulin, $\gamma$ chain of protein $\mathrm{C} 8$ of the complement cascade), cholesterol and pregnenolone (bound to apolipoprotein $\mathrm{D}$ ), pheromones (bound to urinary proteins in mouse and rat), and odorants (bound to odorant binding protein). The nature of these ligands suggests a role in cell regulation. ${ }^{28}$ However, many lipocalins have still to be assigned a function, in particular the recently discovered ones, for which little information is yet available (three dimensional structure unknown, physiological ligand unknown).

The homology of one protein with a group of proteins of known biological function or activity can often shed light on its own function or activity in the cell where it is expressed. A possible role, transport of lipid molecules, was suggested for tear lipocalin in view of the observed relation between structure and function: what then was the ligand, unable to survive in a hostile hydrophilic environment, that used this shell for transport to a physiological receptor? Retinol was proposed. At the same time tear lipocalin was found to be expressed in minor salivary glands, von Ebner's glands, located around the circumvallate and foliate papilla of the human tongue. ${ }^{29}$ In this tissue, tear lipocalin was named VEGP. The possible ligand might be a lipophilic sapid molecule, such as a bitter compound, able to be transported by the protein to the taste buds ${ }^{30}$ or a fatty acid. ${ }^{31}$ However, studies on the expression of the TL gene in different organs lent further insight into the biological function of TL/VEGP. An expression was observed in the submandibular gland, in the secretory units of the tracheal epithelium ${ }^{4}$ and in the prostate. ${ }^{32}$ These results already suggested a possible role of the protein as a protection factor for the epithelia.

Given all these results, attention was focused on the cavity to try to find the molecule that would best fit inside. The recently published paper of Van't Hof et al ${ }^{21}$ attributes a convincing physiological function to this protein: cysteine proteinase inhibitor.

This function is cleverly hypothesised and nicely demonstrated. (i) Among the few stretches of sequence strongly conserved in the members of the lipocalin family, the first stretch, located near the $\mathrm{N}$ terminus, contains the sequence G $x$ W Y shared by almost all lipocalins. The side chain of tryptophan (W), present in all members, has been proposed as a part of the ligand binding site. The amino acids found in positions 11 to 18 are as follows: QDVSGTWY. This sequence includes $\mathrm{Q} x \mathrm{~V} x \mathrm{G}$, a motif also encountered in the cystatin family.

(ii) As previously indicated, the cystatin superfamily members contain highly conserved domains participating in the active site, located far apart in the amino acid sequence but spatially contiguous on the surface of the protein (among these, $\mathrm{Q} x \mathrm{~V} x \mathrm{G}$ from 55 to 59 , and $\mathrm{W}$ at position 106).

Studies with two chemically synthesised peptides, one containing residues $3-21$ of TL and one containing the three papain binding domains of cystatin $\mathrm{C}$ demonstrated the involvement of the 3-21 amino acids of TL in protease inhibition. The antiprotease activity of TL was demonstrated on purified fractions of lacrimal fluid and the complementary experiments (amino acid analysis, $\mathrm{N}$ terminal sequencing, western blot analysis) suggest that the antiprotease effect was not caused by any potent contamination that had been co-purified.

These results question the evolutionary process leading to two unrelated groups of proteins able to perform very similar functions. The lipocalins and the cystatins not only display different three dimensional structures but have negligible sequence homology, apart from the previously described motif. Preparation and purification of recombinant cystatin and tear lipocalin would allow comparison of their respective cysteine proteinase inhibitor activities and their mechanism of action.

These results also call for re-examination of the functions of the members of the lipocalin family. Have their activities changed during evolution? Seven members of the lipocalin family ${ }^{5}$ have clustered their corresponding genes on human chromosome 9 . They are thought to have arisen by divergence of sequence and function. Until now, attention had been focused mainly on their role in cell regulation. The paper by van't Hof et al reminds us that we should extend our thinking to other fundamental biological processes.

The mystery seems therefore to be unravelled and a coherent antibacterial function can be attributed to tear lipocalin: its cysteine proteinase inhibitor function makes the widespread occurrence of the protein in body fluids such as tears, saliva, bronchial mucus, and prostate fluid unsurprising. Further studies will be needed to evaluate the involvement of tear lipocalin in the defence function.

\section{Conclusions}

Lysozyme, lactoferrin, cystatin S, secretory IgA, and tear lipocalin (whose protective function has recently been described) are involved in corneal and conjunctival epithelium defence but are also present in other mucosal secretions. However, their tear specific distribution indicates that this composition is well adapted to the protective function of the corneal and conjunctival epithelium.

Supported in part by grants from the Centre Hospitalier Universitaire of Clermont Ferrand (UF No 8061) and by the local committee of La Ligue Nationale Contre le Cancer.

ANNE-MARIE FRANÇOISE GACHON ERIC LACAZETTE

Laboratoire de Biochimie Médicale, Unité INSERM U 384, 28, Place Henri Dunant, BP 38, 63001 Clermont Ferrand Cedex, France 
1 Brandtzaeg P. Molecular and cellular aspects of the secretory immuno-

globulin system. APMIS 1995;103:1-19.
2 Peters CW, Kruse U, Pollwein R, et al. The human lysozyme gene. Sequence Peters CW, Kruse U, Pollwein R, et al. The human lysozyme gene. Sequence
organization and chromosomal localization. Eur f Biochem 1989;182:507-16.

3 Teng CT, Pentecost BT, Marshall A, et al. Assignment of the lactotransferrin gene to human chromosome 3 and to mouse chromosome 9. Somat Cell Mol Genet 1987;13:689-93.

4 Ressot C, Lassagne H, Kemeny JL, et al. Tissue expression of tear lipocalin in humans. In: Sullivan DA, ed. Lacrimal gland, tear film and dry eye syndrome. Advances in Experimental Medicine and Biology. New York: Plenum Press (in press) 5 Lassagne H, Ressot C, Mattei MG, et al. Assignment of the human tear
lipocalin gene (LCN1) to 9q34 by in situ hybridization. Genomics 1993;18: $160-1$.

6 Lassagne H, Nguyen VC, Mattei MG, et al. Assignment of LCN1 to human chromosome 9 is confirmed. Cytogenet Cell Genet 1995;71:104.

7 Benger JC, Teshima I, Walter MA, et al. Localization and genetic linkage of the human immunoglobulin heavy chain genes and the creatine kinase the human immunoglobulin heavy chain genes and the creatine kinase
brain $(\mathrm{CKB})$ gene: identification of a hot spot for recombination. Genomics 1991;9:614-22.

8 Krajci P, Grzeschik KH, Geurts van Kessel AH, et al. The human transmembrane secretory component (poly-Ig receptor): molecular cloning, restriction length fragment polymorphism and chromosomal sublocalization. Hum Genet 1991;87:642-8.

9 Max EE, McBride OW, Morton CC, et al. Human J chain gene: chromosomal localization and associated restriction fragment length polymorphism. Proc Natl Acad Sci USA 1986;83:5592-6.

10 Saitoh E, Isemura S, Sanada K. Inhibition of calcium carbonate precipitation by human salivary prolin-rich phosphoproteins. Arch Oral Biol 1985;30:641-3.

11 Schnittiger S, Gopal Rao VVN, Abrahamson M, et al. Cystatin C (CST3), the candidate gene for hereditary cystatin $\mathrm{C}$ amyloid angiopathy (HCCAA) and other members of the cystatin gene family are clustered on chromosome 20p11.2. Genomics 1993;16:50-5.

12 Dracopoli NC, O'Connell P, Elsner TL, et al. The CEPH consortium linkage map of human chromosome 1. Genomics 1991;9:686-700.

13 Nguyen VC, Aubert JP, Gross MS, et al. Assignment of human tracheo-bronchial mucin gene(s) to $11 \mathrm{p} 15$ and tracheo-bronchial mucintracheo-bronchial mucin gene(s) to $11 \mathrm{p} 15$ and tracheo-bronchial
related sequence to chromosome 13. Hum Genet 1990;86:167-72.

14 Schenkels LCPM, Veerman ECI, Nieuw Amerongen AVN. Biochemical composition of human saliva in relation to other mucosal fluids. Crit Rev Oral Biol Med 1995;6:161-75.

15 Holly FJ, Lemp MA. Wettability and wetting of corneal epithelium. Exp Eye Res 1971;11:239-50.

16 Gipson IK, Inatomi T. Cellular origin of mucin of the ocular surface. In:
Sullivan DA, ed. Lacrimal gland, tear film and dry eye syndrome. Advances in Experimental Medicine and Biology. New York: Plenum Press (in press).

17 Abrahamson M, Barret AJ, Salvesen G, et al. Isolation of six cysteine proteinase inhibitors from human urine. Their physicochemical and enzyme kinetic properties and concentrations in biological fluids. $f$ Biol Chem 1986;261:11282-9.

18 Barka T, Asbell PA, van der Noen H, et al. Cystatins in human tear fluid. Curr Eye Res 1991;10:25-34.

19 Isemura S, Saitoh E, Sanada K, et al. Identification of full-sized forms of salivary (S type) cystatins (cystatin $\mathrm{SN}$, cystatin $\mathrm{SA}$, cystatin $\mathrm{S}$, and two phosphorylated forms of cystatin S) in human whole saliva and determination of phosphorylation sites of cystatin S. F Biochem 1991;110:648-54.

20 Henskens YM, Veerman EC, Niew Amerongen AV. Cystatins in health and disease. Biol Chem Hoppe Seyler 1996;377:71-86.

21 Van't Hof W, Blankenvoorde MFJ, Veerman ECI, et al. The salivary lipocalin von Ebner's gland protein is a cysteine proteinase inhibitor. $\mathcal{F}$ Biol Chem 1997;272:1837-41.

22 Gachon AMF, Verrelle P, Betail G, et al. Immunological and electrophoretic studies of human tear proteins. Exp Eye Res 1979;29:539-53.

23 Fullard RJ. Identification of proteins in small tear volumes with and without size exclusion HPLC fractionation. Curr Eye Res 1988;7:163-79.

24 Delaire A, Lassagne H, Gachon AMF. New members of the lipocalin family in human tear fluid. Exp Eye Res 1992;55:645-7.

25 Lassagne H, Gachon AMF. Cloning of a human lacrimal lipocalin secreted in tears. Exp Eye Res 1993:56:605-9.

26 Redl B, Holzfeind P, Lottspeich F. cDNA cloning and sequencing reveals human tear prealbumin to be a member of the lipophilic-ligand carrier protein superfamily. $\mathcal{F}$ Biol Chem 1992;267:20282-7.

27 Godovac-Zimmermann J. The structural motif of $\beta$-lactoglobulin and retinol-binding protein: a basic framework for binding and transport of small hydrophobic molecules. TIBS 1988;13:64-6.

28 Flower DR. The lipocalin protein family: a role in cell regulation. FEBS Lett 1994;354:7-11.

29 Bläker M, Kock K, Ahlers C, et al. Molecular cloning of human von Ebner's gland protein, a member of the lipocalin superfamily highly expressed in lingual salivary glands. Biochim Biophys Acta 1993;1172:131-7.

30 Schmale H, Holtgreve-Grez H, Christiansen H. Possible role for salivary gland protein in taste reception indicated by homology to lipophilic-ligand

31 Glasgow BJ, Abduragimov AR, Farahbakhsh ZT, et al. Tear lipocalins bind a broad array of lipid ligands. Curr Eye Res 1995;14:363-72.

32 Holzfeind P, Merschak P, Rogatsch H, et al. Expression of the gene for tear lipocalin/von Ebner's gland protein in human prostate. FEBS Lett 1996;395:95-8. 